\title{
Sistema de análise estequiométrica para produção de sabão a partir do óleo vegetal residual: uma estratégia para redução do impacto ambiental
}

\author{
Stoichiometric analysis system for production of soap from vegetable oil residual: \\ a strategy for reducing environmental impact \\ Sérgio Thode Filho'; Marcelo Fonseca Monteiro de Sena²; Elmo Rodrigues da Silva3; \\ Gabrielle Borges Cabral'; Fabíola da Silveira Maranhão5 \\ ' Doutorando em Meio Ambiente pelo PPG-MA da UERJ, Professor do Instituto Federal de Educação, \\ Ciência e Tecnologia do Rio de Janeiro (IFRJ), Campus Duque de Caxias - RJ. \\ ${ }^{2}$ Docente do Instituto Federal do Rio de Janeiro (IFRJ). \\ ${ }^{3}$ Docente do curso de Pós-Graduação em Meio Ambiente - UERJ \\ ${ }^{4}$ Discente do Curso Técnico em Petróleo e Gás (IFRJ), bolsista pesquisadora do (LMGR). \\ ${ }^{5}$ Discente do Curso Técnico em Polímeros (IFRJ), bolsista pesquisadora do (LMGR).
}

\section{Resumo}

A fabricação de sabão utilizando óleo vegetal residual é uma das formas de evitar que este alcance os corpos hídricos e o solo na sua forma prejudicial, mitigando assim seus impactos ao meio ambiente. Sua fabricação artesanal não requer muitos investimentos e conhecimentos, pois é um processo simples que utiliza insumos e equipamentos utilizados no cotidiano da maioria das pessoas. Este trabalho teve por objetivo apresentar os resultados de um sistema de análise que proporcionasse uma razão ótima entre os insumos utilizados na produção de sabão a partir do óleo vegetal residual. Baseado nestes resultados, foi viabilizada a produção de um sabão com características físicas e químicas aceitáveis, de qualidade satisfatória semelhantes aos industrializados e, indiretamente, a conscientização quanto ao descarte inadequado do óleo vegetal.

Palavras-chave: óleo vegetal, saponáceos, análise estequiométrica, impacto ambiental.

\begin{abstract}
The manufacture of soap using waste vegetable oil is one of the ways to avoid it reaches water bodies and soil in its ruling, thus mitigating their impacts on the environment. His artisanal does not require much investment and knowledge, it is a simple process that uses inputs and equipment used in the daily lives of most people. This work aims at presenting the results of an analysis system that would provide a good reason between the inputs used in the production of soap from vegetable oil waste. Based on these results, it was made possible the production of a soap with acceptable physical and chemical characteristics, of satisfactory quality similar to industrialized and, indirectly, the awareness of the inappropriate disposal of vegetable oil.
\end{abstract}

Keywords: vegetable oil, soaps, stoichiometric analysis, environmental impact. 


\section{INTRODUÇÃO}

Uma das questões presentes nas determinações da PNRS, diz respeito ao descarte do óleo vegetal de frituras gerado nas residências e estabelecimentos comerciais. No Brasil estima-se a produção de três bilhões de litros de óleo vegetal comestível por ano. Deste total, apenas $2,5 \%$ é reutilizado para alguma finalidade, enquanto que o restante é indevidamente descartado, pela população e indústrias, nos solos, corpos d'água, rede de esgotos, ou ainda, incinerados (ABIOVE, 2012).

No município do Rio de Janeiro, mais de 20 milhões de litros de óleo vegetal são consumidos por ano. Em 2008, apenas 50 mil litros, ou 0,2\%, foram reciclados. Em 2009, com a implementação do Programa de Reaproveitamento de Óleos Vegetais do Estado do Rio de Janeiro (PROVE), foram recolhidos cerca de 60 mil litros nos três primeiros meses do ano (FOLHA DO CENTRO, 2009).

Os óleos vegetais são amplamente utilizados pela população brasileira, seja em nível doméstico, comercial ou industrial. Ao final de seu processamento, o óleo remanescente é descartado, muitas vezes, de forma incorreta, sendo liberado nos efluentes ou diretamente no solo, tornando-se um resíduo potencialmente poluidor (RABELO e FERREIRA, 2008; SABESP, 2011).

Não há um consenso quanto à forma ideal de descarte do óleo vegetal residual. A orientação mais comum quanto ao seu descarte é o acondicionamento do óleo em um recipiente fechado, como uma garrafa pet, seguido do descarte no lixo domiciliar. A desvantagem deste procedimento é a incerteza de que este resíduo não alcance os corpos hídricos e solos, uma vez que a coleta de lixo domiciliar por caminhões compactadores pode causar o rompimento dos recipientes (RABELO e FERREIRA, 2008).

Segundo a Folha do Amapá (2007), uma forma mais segura de descarte de óleo vegetal residual é a entrega deste em um posto de coleta, para posterior reutilização na fabricação de biodiesel ou sabão. Além desta, a fabricação de sabão na própria residência tem se mostrado como uma possibilidade alternativa. A fabricação de sabão utilizando óleo vegetal residual é uma forma de evitar que este alcance os corpos hídricos e o solo na forma prejudicial, mitigando assim seus impactos no meio ambiente.

O óleo vegetal residual, caso seja descartado pela rede de esgoto, pode provocar o entupimento das tubulações e aumentar em até $45 \%$ os custos de tratamento. O material pode ocasionar também sérios danos ambientais ao alcançar os corpos d'água, pois o óleo forma uma camada na superfície da água que impede a entrada da luz solar, diminuindo a fotossíntese, o oxigênio dissolvido, $\mathrm{e}$, consequentemente, provoca a morte da fauna local (QI et al., 2009).

Os solos são também impactados pelo óleo, pois este impermeabiliza-o, desestruturando e causando enchentes (FIGUEIREDO, 1995; FOLHA DO AMAPÁ, 2007; NOGUEIRA E BEBER, 2009; GALBIATI, 2012). Para dar conta destes problemas, há que se buscar alternativas tecnológicas e gerenciais de controle e prevenção da poluição como, por exemplo, o reuso do óleo vegetal residual de fritura no processo de saponificação. O sabão é um produto obtido a partir de uma hidrólise alcalina de uma gordura de origem vegetal ou animal. Além dos saponáceos, como sabão em barra, detergente líquido e sabão pastoso, o óleo vegetal residual pode ser matéria prima para outros produtos tais como: biodiesel, óleo para engrenagens, glicerina automotiva, tintas, etc. (NOGUEIRA e BEBER, 2009; WILDNER \& HILLIG, 2012).

Apesar de um número bastante reduzido de segmentos e empresas utilizarem o óleo vegetal residual como matéria-prima de seus produtos, este número tende a aumentar em um futuro próximo devido às exigências na nova Política Nacional de Resíduos Sólidos no Brasil e dos prováveis incentivos governamentais (NOGUEIRA e BEBER, 2009; BRASIL, 2010; WILDNER e HILLIG, 2012). A responsabilidade compartilhada pelo ciclo de vida dos produtos abrange fabricantes, importadores, distribuidores e comerciantes, consumidores e os municípios, que são os titulares dos serviços públicos de limpeza urbana e manejo de resíduos sólidos. Isto significa dividir as responsabilidades entre sociedade, iniciativa privada e poder público (MONTEIRO e ZVEIBIL, 2001; SILVA et al., 2010; MEIRELES e ALVES, 2011). Este trabalho teve por objetivo comparar cinco relações distintas entre os insumos utilizados para produção de saponáceo a partir de óleo vegetal residual, através da determinação da melhor proporção estequiométrica (razão ótima) entre os insumos utilizados.

\section{METODOLOGIA}

Os materiais utilizados para esta análise foram: 5 béquer de $500 \mathrm{~mL}, 1$ bastão de vidro, 1 proveta de $100 \mathrm{~mL}$, fita tornassol para marcação de 
pH, espátula, óculos, luva e mascara de segurança. Reagentes utilizados: $\mathrm{NaOH}$ (soda cáustica), $\mathrm{H}_{2} \mathrm{O}$ (água) e óleo vegetal residual de frituras. Ressaltase que o óleo empregado é uma matéria prima de origem heterogênea e bastante saturada. Não foram feitos testes químicos de acidez, peróxido, saponificação ou iodo para caracterizar este óleo. Verificou-se apenas os aspectos físicos, tais como: viscosidade, cor, odor e partículas em suspensão. O óleo vegetal residual utilizado neste trabalho foi oriundo de doações voluntárias de moradores de diversas localidades do Município de Duque de Caxias, Rio de Janeiro. O material foi entregue, necessariamente acondicionado em garrafas polietileno PET de $500 \mathrm{~mL}$ a $2 \mathrm{~L}$ no Laboratório Multidisciplinar de Gerenciamento de Resíduos, situado no Instituto Federal de Educação, Ciência
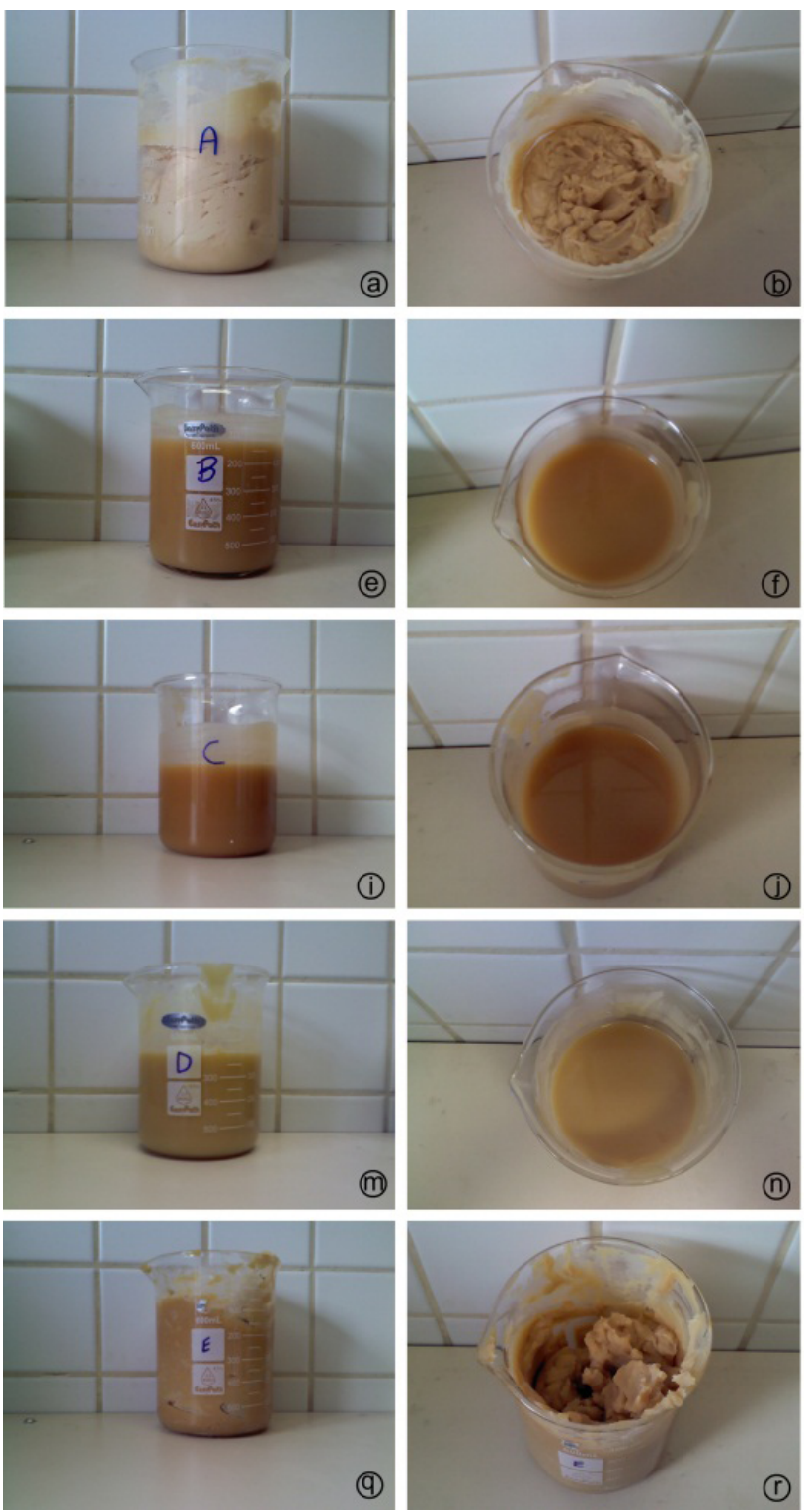

e Tecnologia do Rio de Janeiro (IFRJ).

No laboratório, procedeu-se com a filtração do óleo doado para retirada dos resíduos sólidos e em seguida acondicionado por um período de dez dias em uma bombona de 300L para decantação. Apos estes processos físicos iniciais procedeu-se com a metodologia de saponificação. Entretanto, as proporções dos reagentes foram modificadas em cada grupo experimental, como segue: Grupo A, composto por $300 \mathrm{~g}$ de $\mathrm{NaOH}, 300 \mathrm{~mL}$ de $\mathrm{H}_{2} \mathrm{O}$ e $300 \mathrm{~mL}$ de óleo residual (Figura $1 \mathrm{a}-\mathrm{d}$ ); Grupo $\mathrm{B}$, composto por $150 \mathrm{~g}$ de $\mathrm{NaOH}, 150 \mathrm{~mL}$ de $\mathrm{H}_{2} \mathrm{O}$ e $300 \mathrm{~mL}$ de óleo residual (Figura $1 \mathrm{e}$-h); Grupo C, composto por $50 \mathrm{~g}$ de $\mathrm{NaOH}, 50 \mathrm{~mL}$ de $\mathrm{H}_{2} \mathrm{O}$ e $300 \mathrm{~mL}$ de óleo residual (Figura 1 i-1); Grupo D, composto por $50 \mathrm{~g}$ de $\mathrm{NaOH}, 100 \mathrm{~mL}$ de $\mathrm{H}_{2} \mathrm{O}$ e $300 \mathrm{~mL}$ de óleo residual (Figura $1 \mathrm{~m}$-p); e Grupo
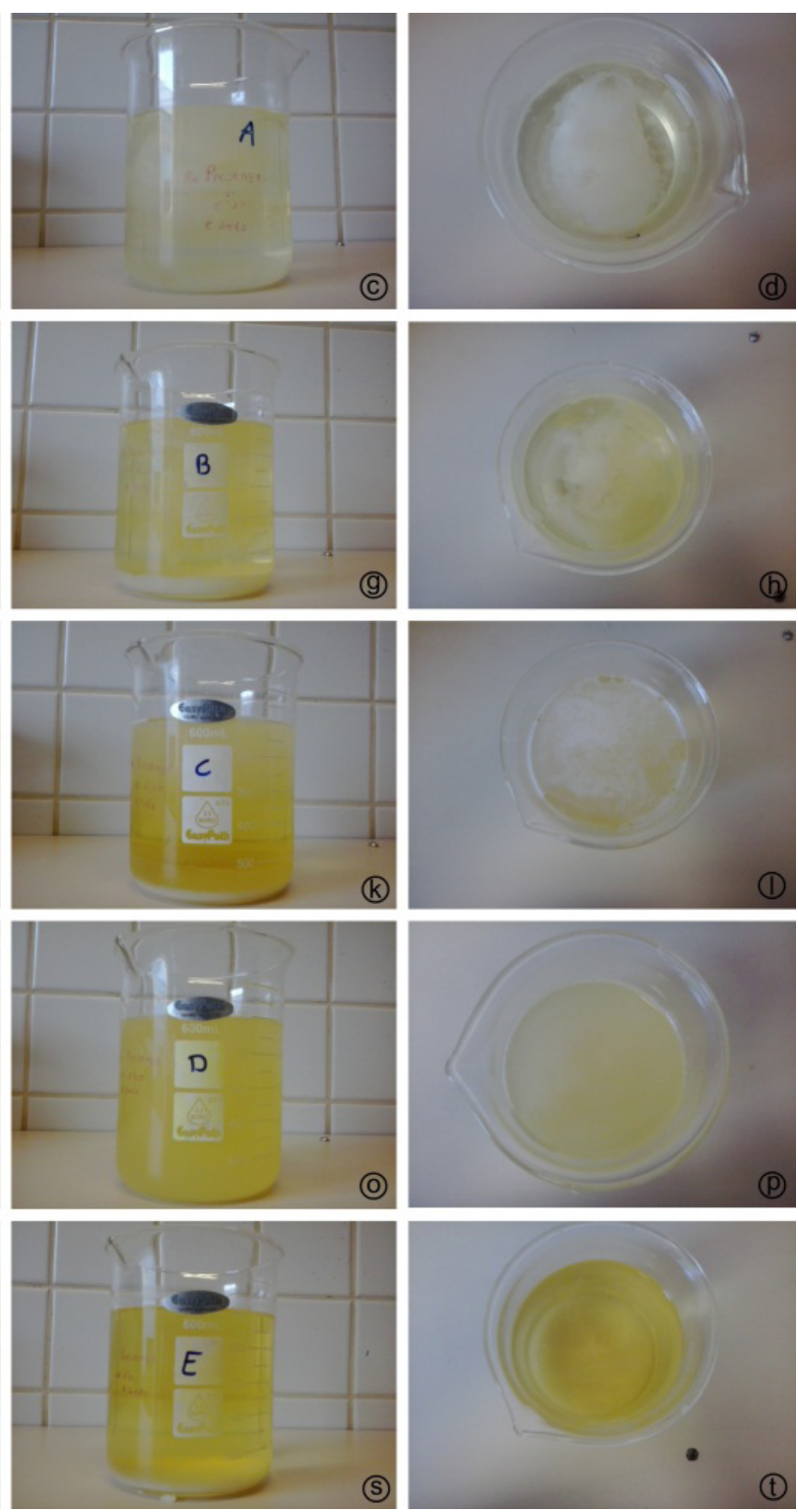

Figura 1. Reação de saponificação dos cinco grupos experimentais separados por diferentes proporções de reagentes. 
E, composto por $100 \mathrm{~g}$ de $\mathrm{NaOH}, 50 \mathrm{~mL}$ de $\mathrm{H}_{2} \mathrm{O}$ e $300 \mathrm{~mL}$ de óleo residual (Figura $1 \mathrm{q}-\mathrm{t}$ ). Todos os grupos experimentais foram analisados $48 \mathrm{~h}$ pós produção para observação qualitativa e quantitativa de óleo sobrenadante, $\mathrm{NaOH}$ livre e $\mathrm{H}_{2} \mathrm{O}$ em excesso. Neste mesmo momento, amostrou-se $30 \mathrm{~g}$ de massa de saponáceo sólido de cada grupo experimental e foi colocado em um béquer com $500 \mathrm{~mL}$ de água. Após repouso de cinco dias, observou-se as características químicas de espuma e verificação visual de presença de óleo na superfície.

\section{RESULTADO E DISCUSSÃO}

Segundo Gouvea et al (2010), esta metodologia destaca-se entre as metodologias pesquisadas, devido a um menor número de reagentes, menor custo e com mesma eficácia de limpeza que os sabões comerciais. Primeiramente, a soda caustica é dissolvida em água, após isto adiciona-se o óleo e então agita-se por 1 hora. O conteúdo é colocado em uma bandeja, onde permanece até adquirir uma consistência rígida. Para Alberici e Pontes (2004), após testar várias receitas de sabão caseiro que empregavam óleo comestível usado, chegou-se à seguinte receita: 4 litros de óleo comestível usado, 2 litros de água, $1 / 2$ copo de sabão em pó, $1 \mathrm{~kg}$ de $(\mathrm{NaOH})$ soda cáustica, $5 \mathrm{~mL}$ de óleo essencial.

Ao inicio da reação de saponificação, no grupo A, pôde-se observar a formação de duas fases, sendo, aparentemente, uma delas água e a outra sabão, e o aumento excessivo da viscosidade da mistura, o que impediu que o processo de produção durasse até o fim, tendo que ser finalizado aos 25 minutos de homogeneização. Visualizou-se excesso de água, em forma de gotículas na amostra, e o excesso de soda, em forma de cristais, a mesma ficou demasiadamente dura e quebradiça, com um aspecto disforme. A reação com os coeficientes estequiométricos do grupo B apresentou uma temperatura elevada $\left(75^{\circ} \mathrm{C}\right)$, que se manteve até o fim da reação (1h depois) e seguiu por $2 \mathrm{~h}$ após a produção, o que pode ser explicado por um excesso de água e soda, que ao reagirem de maneira exotérmica um com o outro, ou seja, gerando calor. Visualizou-se o excesso de água, em forma de gotículas, e de soda, em forma de cristais, a mesma ficou dura e quebradiça.

Em contrapartida, a reação com os coeficientes estequiométricos do grupo $\mathrm{C}$ mostrou uma temperatura elevada $\left(60^{\circ} \mathrm{C}\right)$, o que pode ser explicado por um excesso de soda e água na mistura, a mesma amostra apresentou uma coloração mais escura que o normal ao final da produção (1h depois), nesse tempo a temperatura havia diminuído, mas ainda havia um pouco de calor. Visualizou-se uma coloração escura, caracterizada pelo aparente excesso de óleo, a mesma ficou bastante mole.

A reação com os coeficientes estequiométricos do grupo D apresentou geração de calor

Tabela 1. Resultado comparativo dos cinco grupos experimentais separados por diferentes proporções de reagentes.

\begin{tabular}{|c|c|c|c|c|}
\hline Grupo & $\begin{array}{c}\text { Espuma } \\
(\mathbf{m L})\end{array}$ & pH & $\begin{array}{c}\text { Presença de } \\
\text { óleo }\end{array}$ & $\begin{array}{c}\text { Presença de Soda } \\
\text { livre }\end{array}$ \\
\hline $\mathrm{A}^{1}$ & 50 & 12 & $\mathrm{~N}$ & $\mathrm{~S}$ \\
$\mathrm{~B}^{2}$ & 35 & 13 & $\mathrm{~N}$ & $\mathrm{~S}$ \\
\hline $\mathrm{C}^{3}$ & 20 & 10 & $\mathrm{~S}$ & $\mathrm{~S}$ \\
\hline $\mathrm{D}^{4}$ & 55 & 10 & $\mathrm{~N}$ & $\mathrm{~N}$ \\
\hline $\mathrm{E}^{5}$ & 35 & 12 & $\mathrm{~S}$ & $\mathrm{~S}$ \\
\hline
\end{tabular}

1 Saponificação conduzida na proporção de $300 \mathrm{~g}$ de $\mathrm{NaOH}, 300 \mathrm{~mL}$ de $\mathrm{H} 2 \mathrm{O}$ e $300 \mathrm{~mL}$ de óleo vegetal residual; 2 Saponificação conduzida na proporção de $150 \mathrm{~g}$ de $\mathrm{NaOH}, 150 \mathrm{~mL}$ de $\mathrm{H} 2 \mathrm{O}$ e $300 \mathrm{~mL}$ de óleo vegetal residual; 3 Saponificação conduzida na proporção de $50 \mathrm{~g}$ de $\mathrm{NaOH}, 50 \mathrm{~mL}$ de $\mathrm{H} 2 \mathrm{O}$ e $300 \mathrm{~mL}$ de óleo vegetal residual; 4 Saponificação conduzida na proporção de $50 \mathrm{~g}$ de NaOH, $100 \mathrm{~mL}$ de $\mathrm{H} 2 \mathrm{O}$ e $300 \mathrm{~mL}$ de óleo vegetal residual; 5 Saponificação conduzida na proporção de $100 \mathrm{~g}$ de $\mathrm{NaOH}, 50 \mathrm{~mL}$ de $\mathrm{H} 2 \mathrm{O}$ e $300 \mathrm{~mL}$ de óleo vegetal residual. 
$\left(50^{\circ} \mathrm{C}\right)$, que ao término da produção (1h depois) já não existia mais, uma coloração mais clara que as da amostra B e C, e, viscosidade regular. Se comparada com processos anteriores de sabão, o grupo $\mathrm{D}$ foi o que mostrou características, durante e pós produção, mais próximas da normalidade. Visualizou-se uma coloração clara, um aspecto rígido e aparentemente sem excesso de água, óleo ou soda.

Observou-se no grupo E que, ao adicionar a água e a soda para formar a solução, a soda não foi toda solubilizada, mesmo após bastante tempo homogeneizando, verificando-se que a mesma possuía características de uma solução saturada e que havia excesso de soda para a quantidade de água. Com a adição do óleo e o inicio da reação de saponificação, observou-se um aumento excessivo na viscosidade, o que impediu a continuidade do processo de mistura após cinco minutos de produção. Observou-se também uma grande geração de calor. Calor este que se manteve por $2 \mathrm{~h}$ após a produção. E, também, uma coloração escura, o que apresenta, aparentemente, pelo fato da amostra ter sido homogeneizada por apenas 5 minutos, o que impediu uma reação de saponificação homogênea e com isso o óleo não pode ser todo consumido. Visualizou-se uma coloração escura, característica de excesso de óleo, também excesso visível de água e um aspecto disforme, muito duro e quebradiço. Os resultados das análises físico-químicas podem ser observados na tabela 1 e na figura 1 .

Segundo Denkov (2004), utilizando-se o método de Bartsch para análise de espuma, que consiste basicamente em agitar manualmente uma proveta contendo uma certa quantidade de líquido várias vezes de forma padronizada em um determinado intervalo de tempo e em seguida apoiá -la em uma superfície plana para anotar a variação de volume do líquido. Para análise do sabão produzido no laboratório, foi feita uma solução de água e sabão, contendo $1,0 \mathrm{~g}$ de sabão e $50 \mathrm{~mL}$ de água. Após solubilidade do sabão, agitou-se vigorosamente dez vezes, de forma padronizada e colocou-se sobre uma bancada para verificação do volume de espuma produzido. Espumas podem ser definidas como sistemas instáveis, que apresentam estrutura bifásica, geralmente gás-líquido, onde a fase gasosa encontra-se distribuída como células envoltas por filmes líquidos. Sendo a agitação de um recipiente com líquido a maneira mais fácil de se criar espuma, uma vez que este processo ocasiona a incorporação de bolhas de ar ao líquido, o que já pode ser caracterizado como uma espuma (FORTUNA, 2010).

Para análise de $\mathrm{pH}$, utilizou-se o método de detecção de $\mathrm{pH}$ por meio do papel de tornassol, mencionado por (Loureiro, 2008; Mataveli, 2010), o qual embora não apresente grande precisão tem uma ampla faixa de viragem e é de aplicação fácil e rápida, o mesmo consiste no preparo de uma solução e na inserção do papel de tornassol para a aferição da mesma, dependendo da cor mostrada pelo papel após a inserção do mesmo à solução, têm-se o valor do $\mathrm{pH}$, a solução a qual inserimos o papel de tornassol consiste em $1 \mathrm{~g}$ de sabão e $100 \mathrm{~mL}$ de água. Foram feitas análises de $\mathrm{pH}$ de 68 sabonetes (42 adultos e 26 infantis), em barra e líquido, por meio de medidor de $\mathrm{pH}$ e fita tornassol, em iguais condições ambientais e água potável. Houve correspondência entre os métodos de aferição do $\mathrm{pH}$. Dos sabonetes para adultos, 30 eram em barra e 12 líquidos. Dos sabonetes em barra, 29 apresentaram $\mathrm{pH}$ variando entre 9 e 10 e, dos líquidos, seis $\mathrm{pH} \square$ 6,9 (VOLOCHTCHUK et al, 2000).

\section{CONCLUSÕES}

A partir da relação estequiométrica proposta nesta pesquisa, percebe-se que a produção artesanal utilizando o óleo vegetal residual é uma medida mitigadora que reduz o impacto ambiental pós-consumo. Existem na literatura diversas receitas propostas, porém analisou-se a possibilidade de trabalhar com uma razão ótima de insumos objetivando uma eficiência no uso dos mesmos, redução de custos e que o produto final (sabão) se encontrasse em condições aceitáveis de uso e comercialização. Constatou-se que a relação (1: $2: 6$ ) do grupo experimental $\mathrm{D}$, isto é, uma parte de $\mathrm{NaOH}$, duas partes de água e seis partes de óleo vegetal residual é a relação considerada ótima entre os insumos. Constatou-se que na relação utilizada, não foram encontradas presença de soda livre, presença de óleo e água que não foram utilizados no processo. Percebeu-se que mesmo sem a utilização de essências ou aromatizantes o produto final apresenta um aspecto físico uniforme, uma textura rígida, uma coloração amarelo pálido, um odor agradável, um índice de espuma satisfatório e um $\mathrm{pH}$ aceitável. Para produção em escala maior, recomenda-se que após dois dias o sabão seja cortado e abrigado da luz. Após doze dias o mesmo estará pronto para uso. Este procedimento se faz necessário para que o $\mathrm{NaOH}$ seja dissipado lentamente e o $\mathrm{pH}$ se estabilize. Recomenda-se que o sabão obtido a partir dos insumos utilizados seja utilizado para limpeza pesada, sendo impróprio para o asseio corporal. 


\section{REFERÊNCIAS}

ABIOVE. Associação Brasileira das Indústrias de Óleos Vegetais. 2012. Disponível em: <http:// www. abiove.com.br/menu_br.html>. Acesso em: 18 jan. 2013.

ALBERICI, R. M., PONTES, F. F. F. 2004. Reciclagem de óleo comestível usado através da fabricação de sabão, São Paulo, Brasil. Engenharia Ambiental: Pesquisa e Tecnologia, 1 (1):73-76.

BRASIL. Lei ${ }^{\circ} 12.305$, de 2 de agosto de 2010. Institui a Política Nacional de Resíduos Sólidos; altera a Lei $\mathrm{n}^{\circ} 9.605$, de 12 de fevereiro de 1998; e dá outras providências.

DENKOV, N. D. 2004. Mechanisms of Foam Destruction by Oil-based Antifoams, Washington, Estados Unidos. Langmuir, 20: 9463-9505.

FIGUEIREDO, P. M. 1995. A sociedade do lixo: os resíduos, a questão energética e a crise ambiental. São Paulo: Unimep, 240p.

FOLHA DO AMAPÁ. 2007. Óleo de cozinha usado contamina solo água e atmosfera, Disponível em: <http://www.folhadoamapa.com.br>. Acesso em: 21 jul. 2012.

FOLHA DO CENTRO. 2009. Esgoto não é lugar de óleo de cozinha. Disponível em: <http://www. jornalfolhadocentro.com.br>. Acesso em: 20 jul. 2012.

FORTUNA, I. Dinâmica de Crescimento de Espumas Molhadas, Universidade Federal do Rio Grande do Sul. Disponível em: < http://www.lume.ufrgs. br/bitstream/handle/10183/23236/000740441. pdf?sequence=1>. Acesso em 14 abr. 2012.

GOUVEA, L. P.; DOURADO, M. T.; JORDÃO, S. J.; MESKO, M. F.; PEREIRA, C. M. P. Reutilização de óleos comestíveis na confecção de sabões: uma alternativa de reciclagem. Disponível em: < http:// www.ufpel.edu.br/cic/2010/cd/cb.htm>. Acesso em 14 abr. 2012.

GALBIATI, A. F. 2005. O gerenciamento integrado de resíduos sólidos e a reciclagem. Minas Gerais, Disponível em: <http://www.redeaguape.org.br>. Acesso em: 21 jul. 2012.

LOUREIRO, R. L. 2002. Caracterização do chorume segundo alguns parâmetros e aplicação do método de eletrofloculação. Monografia do Curso de Química da Universidade Federal do Espírito Santo, Vitória, ES. 44p.

MATAVELI, M.; MORAES, GV; STREIT JUNIOR, DP; RIBEIRO, RP; GASPARINO, E. 2010. Qualidade do sêmen em tilápia do Nilo (Oreochromis niloticus), alimentada com dietas contendo diferentes níveis de vitamina C. Paraná, Brasil. Acta Scientiarum Animal Sciences, 32 (3): 345-349.

MEIRELES, M. E. F.; ALVES, J. C. M. Gestão de resíduos: As possibilidades de construção de uma rede solidária entre associações de catadores de materiais recicláveis. In. VII Congresso Nacional de Excelência em Gestão, 2011.

MONTEIRO, J. H. P.; ZVEIBIL, V. Z. Manual de gerenciamento integrado de resíduos sólidos. Rio de Janeiro: IBAM, 2001.

NOGUEIRA, G. R.; BEBER, J. 2009. Proposta de metodologia para o gerenciamento de óleo vegetal residual oriundo de frituras. Tese de Mestrado em Bioenergia. Universidade Estadual do Centro-Oeste do Paraná, Irati. Disponível em: <http://www.unicentro.br>. Acesso em: 14 abr. 2012.

QI, D.; WANG, Q.; WANG, QI.; HUANG, Q.; YIN, P. Study on Saponification Technology of Waste Edible Oil. In: Bioinformatics and Biomedical Engineering, 2009. ICBBE 2009. 3rd International Conference on, Beijing, China, p. 1-4.

RABELO, R. A.; FERREIRA, O. M. 2008. Coleta seletiva de óleo residual de fritura para aproveitamento industrial. Disponível em: <http://www.ucg. br>. Acesso em 14 abr. 2012.

SABESP. 2011. Reciclagem de óleo de cozinha. Disponível em: <http://site.sabesp.com.br>. Acesso em: 14 abr. 2012.

SANTO, M. 2012. Perfuração de poços de petróleo: fluidos de perfuração, Rio de Janeiro, Brasil. Revista de divulgação do Projeto Universidade Petrobras e IF Fluminense, (2) 1, 121-127.

SILVA, E. R.; CARMO, E. C. L.; GONÇALVES, P.; BENTO, R. F. P.; MATTOS, U. A. O. Planejamento participativo para a implantação da coleta seletiva solidária no estado do Rio de Janeiro, RJ: Ações e resultados. In. VI Congresso Nacional de Excelência em Gestão, 2010. 
VOLOCHTCHUK, O. M; FUJITA, E. M.; FADEL, A. P. C.; AUADA, M.P.;

ALMEIDA, T.; MARINONI, L. P. 2000. Variações do $\mathrm{pH}$ dos sabonetes e indicações para sua utilização na pele normal e na pele doente, Rio de Janeiro, Brasil. Anais Brasileiros de Dermatologia, 75 (6): 697-703.

WILDNER, L. B. A.; HILLIG, C. 2012. Reciclagem de óleo comestível e fabricação de sabão como instrumentos de educação ambiental. Rio Grande do Sul, Brasil. Revista Eletrônica em Gestão, Educação e Tecnologia Ambiental, 1: 813-824. 